\title{
ROCHAS METASSEDIMENTARES, GEOLOGIA ESTRUTURAL E METAMORFISMO DA SUITTE METAMÓRFICA PORONGOS NA ÁREA DA ANTIFORME CAPANÉ, CACHOEIRA DO SUL - RS
}

\author{
JULIANA CHARÃO MARQUES* , HARDY JOST* , ARI ROISENBERG** E JOSÉ CARLOS FRANTZ**
}

\begin{abstract}
METASEDIMENTARY ROCKS, STRUCTURE AND METAMORPHISM OF THE PORONGOS METAMORPHIC SUITE IN CAPANE ANTIFORM AREA. CACHOEIRA DO SUL, RS (SOUTHERN BRAZIL). The Capane Antiform is a structure sustained by rocks of the Porongos Metamorphic Suite, which consists of a thick unit of metapelites, with minor quartzites, and lenses of marble and quartz-pebble metaconglomerates, followed by a unit of mafic to felsic metavolcanic rocks, late to post-kinematic granitic intrusions, and tectonically imbricated ultramafic and alkaline gneiss bodies. The metasedimentary rock association is interpreted as having been originally deposited under shallow marine environment, and the volcanics erupted under sub-aqueous conditions. Both rock assemblages are probably Neoproterozoic in age. The textural and structural features of the Capané Antiform rocks indicate predominant mylonitic and non-coaxia deformation. The $S_{1}$ e $S_{2}$ foliation formed probably during the Brasiliano Cycle by shearing during tangential displacement $\left(D_{2}\right)$ and northeastern verging thrusting, parallel to the Dom Feliciano Belt. Zones of higher strain and imbrication are preserved as long and narrow zones of phyllonites and ultramylonites, in their turn gently folded during later stages. The locally preserved $S_{1}$ foliation has mineral assemblages of low to medium amphibolite facies, while the dominant $S_{2}$ of médium to high greenschist fácies. Rocks of low greenschist fácies occur in the eastern limb of the antiform and could represent younger sections of the basin, located at the top of the sequence.
\end{abstract}

Key-words: Metasedimentary rocks, mylonitization, retrograde metamorphism, Brasiliano Cycle, Capané Antiform, Porongos Metamorphic Suite

RESUMO A unidade metassedimentar da Suíte Metamórfica Porongos na área da Antiforme Capané é caracterizada por uma espessa unidade de metapelitos com intercalações de quartzito e lentes de mármore e de metaconglomerado oligomítico, seguida de metavulcânicas máficas a félsicas, intrusões graníticas tardi a pós-cinemáticas e corpos tectonicamente imbricados de rochas ultramáficas e gnaisses alcalinos. A natureza das rochas metassedimentares sugerem sedimentaç̃o em ambiente de mar raso, com vulcanismo sub-aquoso. As rochas da antiforme são interpretadas como de idade neoproterozóica. As feições texturais e estruturais das rochas da Antiforme Capané indicam uma deformação não-coaxial e milonítica, com formação de duas foliações. A foliação $S_{1}$ é local e está superposta por $S_{2}$, predominante. Ambas foram formadas por cisalhamento durante 0 transporte tangencial para nordeste, paralelo ao Cinturão Dom Feliciano. As zonas de alto strain se destacam como longas cristas de milonitos e filonitos. Todo o conjunto foi dobrado de forma suave nos estágios finais da deformação, gerando a antiforme. As associações minerais de $S_{1}$ indicam metamorfismo na fácies anfibolito inferior e de $S_{1}$ na fácies xisto verde médio a superior. No flanco leste, rochas com associações minerais resultantes de graus metamórficos contrastantes colocadas lado-a-lado e, no flanco oeste, as ocorrências de rochas ultramáficas e gneisses alcalinos são evidências de blocos tectonicamente justapostos. Rochas que ocorrem na porção leste da antiforme, próximo à zona de charneira, com associações minerais da fácies xisto verde inferior podem representar porções de topo da sequência.

Palavras-chave: Rochas metassedimentares, milonitização, metamorfismo retrogressivo, Ciclo Brasiliano, Antiforme Capané, Suíte Metamórfica Porongos

INTRODUÇÃO Nos últimos anos, diversos trabalhos têm sido dedicados ao entendimento das zonas de cisalhamento formadas durante as fases finais do Evento Brasiliano no Cinturão Dom Feliciano. No entanto, a maioria dos estudos se concentrou no extremo leste do cinturão, constituído essencialmente por rochas graníticas, deixando à margem a faixa de rochas metassedimentares da Suíte Metamórfica Porongos, situada imediatamente a oeste, exceto na região de Santana da Boa Vista, anteriormente estudada por Jost (1981), Porcher \& Fernandes (1990) e Porcher (1992).

A Suíte Metamórfica Porongos (Jost \& Bitencourt 1980) ocorre na porção central do Escudo Sul-rio-grandense, e é constituída por rochas supracrustais distribuídas ao longo de uma faixa de orientação NE com cerca de $150 \mathrm{~km}$ de comprimento e $20 \mathrm{~km}$ de largura (Fig. 1). A suíte está parcialmente coberta por rochas sedimentares da Bacia do Camaquã, de idade neoproterozóica a eopaleozóica e, no extremo norte, por rochas da Bacia do Paraná..

Na região de Santana da Boa Vista, a Suíte Metamórfica Porongos sobrepõe-se discordantemente aos Gnaisses Encantadas e granitóides milonitizados, interpretados como embasamento do Cinturão Dom Feliciano (Jost 1981, Porcher \& Fernandes 1990, Porcher 1992). No extremo sul, Remus et al. f 1987) descrevem zonas de cavalgamento com imbricações de rochas do embasamento no interior das supracrustais.

A Antiforme Capané localiza-se na porção setentrional da área de ocorrência da Suíte Metamórfica Porongos (Fig. 1). A estrutura é sustentada por um variado conjunto litológico afetado por deformação por cisalhamento, a qual é responsável pela intercalação tectônica de rochas ultramáficas mantélicas e gnaisses alcalinos no interior da sucessão de rochas supracrustais (Marques 1996). Este artigo visa descrever as características litológicas, estruturais e de metamorfismo das rochas da antiforme e contribuir para o entendimento do contexto tectônico de parte do Cinturão Dom Feliciano.

GEOLOGIA DA ANTIFORME CAPANÉ O mapea-mento geológico na escala 1:25000 de parte da Antiforme Capané permitiu subdividir as rochas supracrustais em duas grandes unidades litológicas, uma dominada por rochas metavulcânicas e outra por rochas metassedimentares. Estas unidades estão orientadas preferencialmente segundo NE-SW e foram intrudidas por corpos de granitóides leucocráticos, hoje estirados em lentes decamétricas dispostas segundo a foliação das encaixantes. Sheets de gnaisses alcalinos e metaultramáficas ocorrem como imbricações (Fig. 2).

A unidade metavulcânica aflora principalmente ao longo do flanco oeste da Antiforme e a metassedimentar está concentrada nas porções central e leste da megaestrutura, mas há amplas interdigitacões entre ambas. A unidade metavulcânica foi subdividida em duas sub-unidades, uma félsica de afinidade calcio-alcalina e outra intermediária a máfica de caráter transicional a toleítico e é interpretado por Marques (1996) e Marques et al. (1998) como tendo ocorrido em parte sob condições sub-aquosas e explosivo e associado à subducção de crosta oceânica sob um continente existente durante o Neoproterozóico. As rochas metassedimentares consistem metapelitos e quartzitos, mais raramente mármores e metaconglomerados. Enquanto os metapelitos se distribuem em grande parte da área da estrutura, os quartzitos e mármores se associam em sucessivas cristas no flanco leste. Os metaconglomerados são restritos ao extremo sudoeste da área.

Os metagranitóides são intrusões calcialcalinas, sin-cinemáticas à deformação principal que afetou a Suíte Metamórfica Porongos e ocorrem na porção central da área (Marques 1996, Marques et al. 1998). O gnaisse alcalino, anteriormente descrito por Hartmann \& Jost (1980) na Antiforme Capané e por Camozzato et al.(1994) próximo à Candiota, extremo sul da Suíte Metamórfica Porongos, é précinemático, está intercalado nas supracrustais e pode representar um magmatismo associado a um evento extensional anterior ou concomitante à formação da bacia (Marques 1996, Marques et al. 1998). As rochas metaultramáficas ocorrem como um alinhamento de lentes situadas ao longo do flanco oeste da antiforme e foram interpretadas como produtos mantélicos, possivelmente partes de um ofiólito desmembrado (Marques 1996, Marques et al. 1996).

Metapelitos Os metapelitos da área estudada se dividem em dois conjuntos que contrastam no grau de recristalização metamórfica. Um conjunto consiste de micaxisto fino a grosso, predominante nos flancos da antiforme, e o outro compreende filitos e ardósias confinados à zona de charneira.

MICAXISTOS Os micaxistos apresentam uma grande diversidade textural e composicional. Em afloramento, são rochas brancas ou em tons de cinza ou amarelo claro e podem apresentar filetes e lentes de

* Instituto de Geociências, Universidade de Brasília, Campus Asa Norte, CEP 70910-900, Brasília, DF, e-mail: jcmarq@guarany.cpd.unb.br, hjost@tba.com.br ** Instituto de Geociências, Universidade Federal do Rio Grande do Sul, Campus do Vale, Av. Bento Gonçalves 9500, CEP 91540-000, Porto Alegre, e-mail:ariberg@if.ufrgs.br 
quartzo segregado por metamorfismo. Esses xistos são compostos por proporções variadas de quartzo, biotita, clorita, mica branca e óxidos de ferro, e frequentemente contém porfiroblastos de granada e mica branca em estrutura micafish, com até $1 \mathrm{~cm}$ de diâmetro, localmente também estaurolita restrita a lentes situadas no flanco oeste.

Os micaxistos com porfiroblastos de granada ou estaurolita diferem dos demais micaxistos em alguns aspectos composicionais, texturais e estruturais. Os xistos sem porfiroblastos são finos a médios e apresentam textura que alterna entre lepidoblástica e granoblástica poligonal (Fig. 3a), a primeira em geral crenulada. Estes xistos são compostos por variadas proporções de mica branca, clorita, biotita e quartzo, com proporções subordinadas de turmalina, epidoto e carbonato (Tabela 1). Já os xistos com porfiroblastos são mais ricos em micas e, por isto, têm textura lepidoblástica dominante, mais raramente granoblástica poligonal e porfiroblástica, e são compostos por mica branca, biotita, clorita, quartzo e porfiroblastos de estaurolita e granada que podem alcançar até $30 \%$ da rocha. Cianita, minerais opacos, zircão, apatita, turmalina e epidoto são subordinados e feldspato potássico e plagioclásio são ocasionais (Tabela 1).

O quartzo ocorre preferencialmente em agregados com forma de fita e textura granoblástica poligonal. Em algumas amostras, principalmente as que contém porfiroblastos, o quartzo é menos abundante, tende a ocorrer disseminado e apresenta contatos suturados e feições de recristalização a partir de agregados resultantes de cominuição periférica.

A mica branca ocorre em lamelas límpidas, em geral com inclusões euédricas de opacos, e define a foliação dos xistos. Porfiroclastos de micafish, com até $1,0 \mathrm{~cm}$ de comprimento, são comuns nos xistos sem estaurolita (Fig. 3b). A biotita ocorre ora como lamelas pequenas, em geral intercrescidas com mica branca e clorita, ora como porfiroblastos de até $1,5 \mathrm{~mm}$ de comprimento e estrutura micafish (Fig. 3c). A clorita está geralmente associada com a biotita, sugerindo ser retrometamórfica, e o mineral é sempre fino e ocorre ora disseminado ora em bandas.

A granada ocorre em porfiroblastos euédricos a subédricos de 0,3 a 7,0 $\mathrm{mm}$ de diâmetro, por vezes fraturados, e rotacionados. Os porfiroblastos comumente contém trilhas de inclusões de minerais opacos que evidenciam a sua textura em snowball (Fig. 3d), além de inclusões de quartzo e cianita. Raramente a granada está parcialmente transformada em uma associação de mica branca, clorita e óxidos de ferro.

Os porfiroblastos de estaurolita variam entre 0,3 e $5,0 \mathrm{~mm}$ de diâmetro, são ovais e possuem bordos circundados por clorita e quartzo em sombras de pressão (Fig. 3d). A mineralogia das sombras de pressão é semelhante à da matriz dos xistos, evidenciando retrometamorfismo e que a estaurolita é anterior à foliação mais proeminente dos xistos.

A cianita é rara e está associada à granada como diminutas inclusões ou prismas periféricos. O zircão também é raro e está incluso em biotita e clorita. A apatita ocorre como inclusões ocasionais em mica branca. Os minerais opacos são euédricos a subédricos e são inclusões em estaurolita, granada e mica branca. Epidoto e turmalina são abundantes apenas nas proximidades de metagranitóides, sugerindo atividade hidrotermal local. O carbonato somente ocorre nos metapelitos quando nas proximidades de lentes de mármore, sugerindo que parte desses resultaram de mistura com sedimentação detrítica e química. Feldspato potássico e plagioclásio foram identificados apenas em uma seção

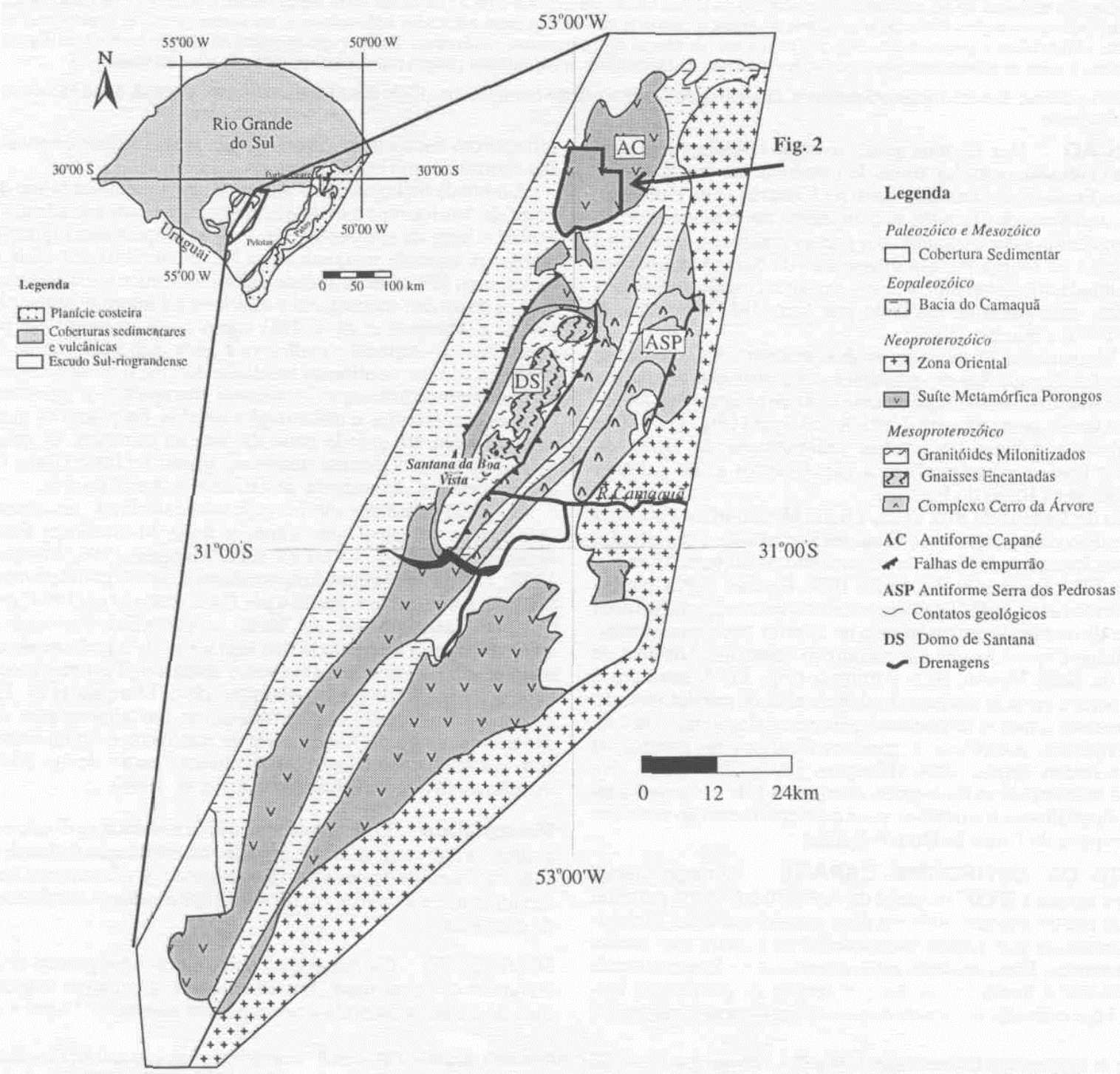

Figura l-Mapa geológico simplificado da parte central do escudo Sul-rio-grandense, mostrando a área de ocorrência da Suite Metamórfica Porongos (extraído de Santos et al. 1989). 
delgada de uma amostra situada na zona de gradação para rochas metavulcânicas, o que sugere que o vulcanismo foi, em parte, contemporâneo com a sedimentação.

FILITOS E ARDÓSIAS Estas rochas são composicionalmente homogêneas, cinza-escuras, friáveis e estão suavemente dobrados. Localmente exibem kink-bands e estão intensamente fraturadas. Mineralogicamente são semelhantes aos micaxistos, mas mais finos e podem ser confundidos com, em afloramento, com as rochas metavulcânicas.

Quartzitos Os quartzitos ocorrem como bancos com centenas de metros de comprimento e de metro a dezenas de metros de espessura, ao longo de um horizonte com cerca de $1.000 \mathrm{~m}$ de espessura, onde estão intercalados em micaxistos. A avançada deformação e recristalização dos quartzitos em algumas áreas os confunde com veios de quartzo de segregacão metamórfica e metagranitóides intensamente cisalhados. Em geral, os quartzitos menos cisalhados são pouco resistentes ao intemperismo, enquanto que os intensamente deformados sustentam cristas persistentes de direção N-NE que podem ser mapeadas até na escala 1: 100.000 .

Os quartzitos variam de puros a impuros, têm aspecto sacaróide fino e são friáveis. Os minerais acompanhantes do quartzo são, em geral, moscovita, clorita e, mais raramente, feldspato em cristais milimétricos disseminados ou agregados em leitos milimétricos. Quando intensamente deformados, os quartzitos são brancos, finos, compactos e bem foliados. A sua textura é milonítica recristalizada e são tectonitos dos tipos $\mathrm{L}>\mathrm{S}$ a $\mathrm{L} \geq \mathrm{S}$ e a lineação resultante tem ângulo de caimento, comumente duplo, inferior a $20^{\circ}$.

Metaconglomerados Duas lentes de metaconglomerado oligomítico ocorrem na transição da zona de charneira para o flanco oeste da antiforme. O metaconglomerado é suportado por clastos arredondados de quartzo leitoso, de tamanho grânulo até seixo bem arredondados, esféricos a elipsoidais. A matriz é constituída por quartzo recristalizado e clorita. Os clastos estão discretamente achatados e fraturados, têm sombras de pressão e contatos suturados por deformação.

Os clastos geralmente apresentam uma foliação interna que varia de orientação de um para outro, indicando que estas rochas originaram por erosão de rochas previamente deformadas. $\mathrm{O}$ contato das lentes de metaconglomerado com as rochas encaixantes é tectônico e a posição estratigráfica e o seu significado no contexto regional são, ainda, incertos.

Mármores Os mármores ocorrem no flanco leste da antiforme, como lentes de centenas de metros de comprimento e espessura variável desde alguns metros até dezenas de metros. Todas as lentes situam-se ao longo de um horizonte estratigráfico aparentemente comum, em meio a metapelitos, alguns calcíferos, intercalados em quartzitos.

Em afloramento e amostra de mão, os mármores variam de puros a impuros e de finos a médios. A estrutura mais proeminente é um bandamento composicional primário marcado pela alternância de finos leitos brancos e cinza claro a escuro, ou mesmo de metamargas. Em geral, as lentes de mármore são cortadas por venulações espaçadas de quartzo.
Mineralogicamente, os mármores são compostos por dolomita, subordinadamente quartzo e mica branca, os níveis de metamarga são formados por carbonato, talco, flogopita, pirita, quartzo e serpentina. A textura dessas rochas é granoblástica, mas localmente podem conter relíquias de textura micrítica original, como identificado em uma lâmina delgada de amostra coletada no flanco leste.

CARACTERÍSTICAS ESTRUTURAIS As feições estruturais observadas nas rochas supracrustais quanto também nos metagranitóides, gnaisses alcalinos e metaultramáficas da Antiforme Capané são idênticas, o que indica que todo o conjunto, foi aparentemente, submetido aos mesmos esforcos regionais. Nas rochas supracrustais, o acamadamento original $\left(\mathrm{S}_{0}\right)$ é paralelo à foliação metamórfica mais proeminente $\left(\mathrm{S}_{2}\right)$, indicando transposição generalizada. A foliação $\left.\mathrm{S}\right]$ está em grande parte obliterada e é de dificil reconhecimento, exceto quando preservada em dobras isoclinais sem raiz, microlithons ou em trilhas de inclusões em minerais. Na maioria das lâminas delgadas, S! é paralela a $\mathrm{S}_{0}$ e S, resultando em uma foliação composta. E esta foliação composta que desenha a megaestrutura antiformal. A estrutura tem um eixo de direç̃o média $\mathrm{NE} 30^{\circ} \mathrm{E}$ e um caimento médio de $20^{\circ}$ para $220^{\circ}$ (Fig. 4a). O flanco de oeste da antiforme mergulha em média $38^{\circ} \mathrm{NW}$ e o de leste $30^{\circ} \mathrm{SE}$. Estas atitudes determinam um ângulo interflancos de aproximadamente $110^{\circ}, o$ que permite definir a estrutura como uma dobra aberta com superficie axial praticamente vertical $\left(86^{\circ} \mathrm{SE}\right)$.

Vista em aerofotografias em escala 1:110.000, a antiforme está cortada por estreitas e longas faixas sub-meridianas de alto strain, as quais são definidas, em afloramentos e lâminas delgadas, por filonitos e ultramilonitos. Estas faixas também estão dobradas em antiforme e representam antigas superfícies de cisalhamento $\left(\mathrm{S}_{1}+\mathrm{S}_{2}\right)$ NE-SW de baixo ângulo de mergulho (Fig. 2b). Em geral, as feições de cisalhamento estão melhor preservadas nos gnaisses alcalinos, metagranitóides e nas rochas metavulcânicas félsicas a intermediárias. A presença destas zonas de cisalhamento são menos evidentes nos metapelitos e nas rochas metavulcânicas máficas e metaultramáficas, exceto pela intensa deformação acompanhada de dobras muito apertadas.

Em afloramento, amostras de mão e lâminas delgadas, todas as rochas da Antiforme Capané mostram características típicas de tectonitos que variam de $\mathrm{S}=\mathrm{L}$ a $\mathrm{S}<\mathrm{L}$. Os tectonitos $\mathrm{L}$ apresentam rods com até vários metros de comprimento (Fig. 5a). Já os tectonitos LS são caracterizados por um bandamento composicional dado pela alternância de níveis ricos em quartzo e feldspatos com níveis mais ricos em minerais máficos. Quando muito deformados, os metapelitos e as rochas ultramáficas são tectonitos $\mathrm{S}$, nos quais a foliação milonítica é marcada pelo alinhamento de micas e talco, respectivamente. Em geral, a foliação milonítica está deformada em dobras isoclinais, apertadas ou abertas e representam fases distintas de deformacão. As dobras isoclinais são mais raras, ocorrem em rochas metavulcânicas ácidas, gnaisses alcalinos e veios de quartzo, afetam exclusivamente $S_{0)}$ e $S$ e são cilíndricas, de limbos rompidos e seus eixos são paralelos a uma lineação de estiramento (Fig. 5b). As dobras apertadas são as mais frequentes, afetam todas as foliações e seus eixos também são paralelos a uma lineação de estiramento. Estas dobras afetam apenas os corpos
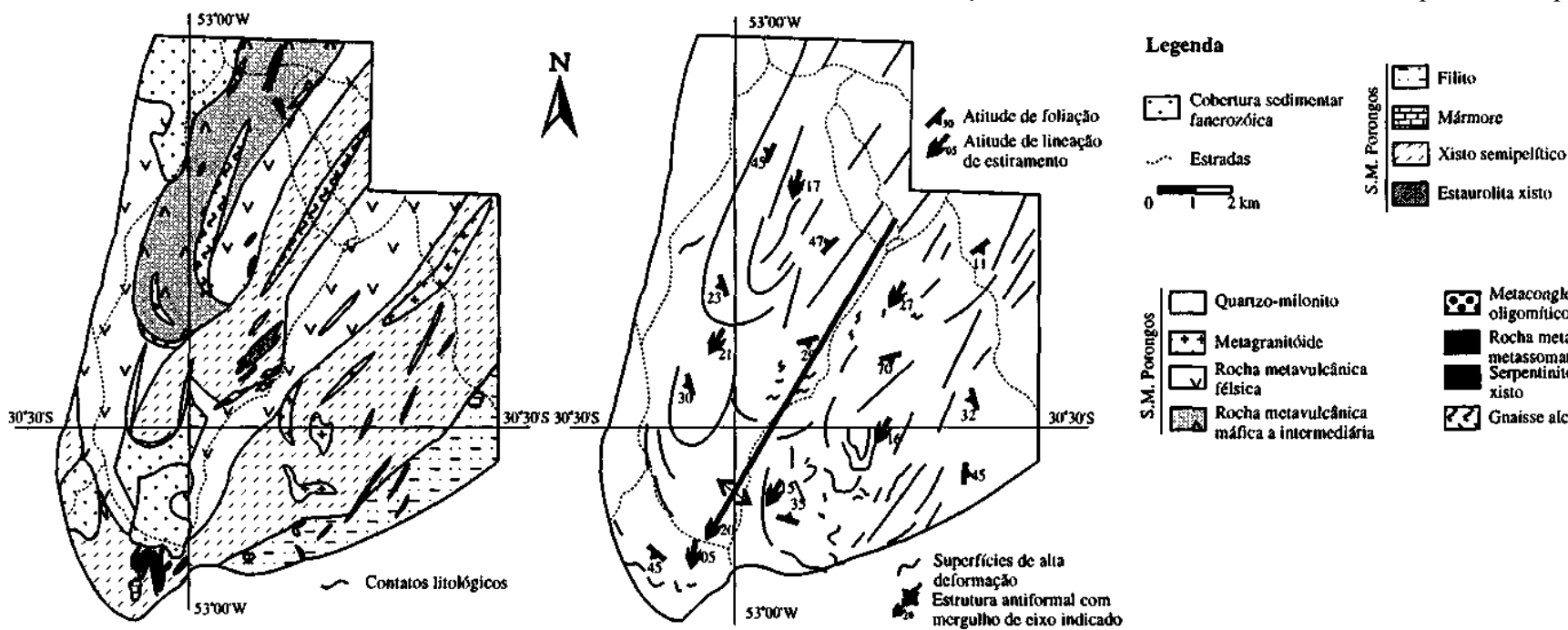

Figura 2 - (a) Mapa geológico simplificado da área estudada (Suíte Metamórfica Porongos, Antiforme Capané); (b) mapa estrutural simplificado da área estudada. 
de metagranitóides alojados nos demais xistos, indicando o caráter sin-cinemático dos mesmos (Marques et al 1998). As dobras abertas são tardias e estão melhor desenvolvidas nos metapelitos, nos quais resultaram na formação de uma clivagem de crenulação espaçada.

A deformação intracristalina se manifesta por extinção ondulante, geração e rotação de subgrãos da maioria dos minerais, assim como pela formação de novos cristais a partir dos fenoclastos de feldspato e quartzo (Fig. 5c). Os fenoclastos estão, em geral, rotacionados e contém sombras de pressão simétricas e assimétricas. Nestas, a recristalização do quartzo é comumente completa, mas é parcial nos feldspatos e minerais máficos. Sombras de pressão também estão bem formadas em fenoclastos de granada, estaurolita, óxidos e sulfetos. Por outro lado, foliação S-C, estrutura micafish, boudins e pods centimétricos a métricos também são feições

Table l - Estimated modal contents (\%) of mica schists of Capané Antiform.

\begin{tabular}{|c|c|c|c|c|c|c|c|}
\hline & \multicolumn{2}{|c|}{ 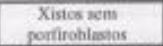 } & \multicolumn{3}{|c|}{ Granade nistos } & \multicolumn{2}{|c|}{$\begin{array}{c}\text { Granadacstaurolita } \\
\text { sasus }\end{array}$} \\
\hline & $\operatorname{Mac}-32$ & Mac-34 & Mac 90 & Mac $9 \mathrm{Xla}_{3}$ & Mac-230 & Mas-36 & Max-770 \\
\hline Quartxo & $45-50$ & 45.50 & 40.45 & $30-35$ & $50-55$ & $30-35$ & $20-25$ \\
\hline Mics Branca & $30-35$ & $10-15$ & $25 \cdot 30$ & 40.45 & $20-25$ & $35-40$ & $35-46$ \\
\hline Biscita & $<1$ & 3-5 & $15-20$ & $10-15$ & $5-10$ & $<5$ & $5-10$ \\
\hline Clorita & $15-20$ & $30-35$ & $3-5$ & 5.10 & trapeo & $5-10$ & $1-3$ \\
\hline Granafa & - & - & - & 3.5 & $5-10$ & $5-10$ & 5.10 \\
\hline Estambita & - & - & - & - & - & $10-15$ & 15.20 \\
\hline Canita & - & - & - & traças & trapes & tragas & тragow \\
\hline Opacos & 1.2 & 3.5 & $5-10$ & $1-2$ & trages & tragas & 3.5 \\
\hline Zircăo & trascos & Irąes & tragos & aragas & trapoox & tragas. & пзуми \\
\hline Apatis: & - & inges & thasos & traças & trapess & ragsot & mages \\
\hline Folitspans & $\ldots$ & - & $\ldots$ & tragos & $5-110$ & - & - \\
\hline Turmalina & - & $\ldots$ & trasos & iragas & - & tuagas & unasese \\
\hline Epidato & $m$ & - & tras 06 & maços & $\ldots$ & magas. & Iragen \\
\hline Carbonatio & trasos: & tragos. & - & - & - & - & $\ldots$ \\
\hline
\end{tabular}
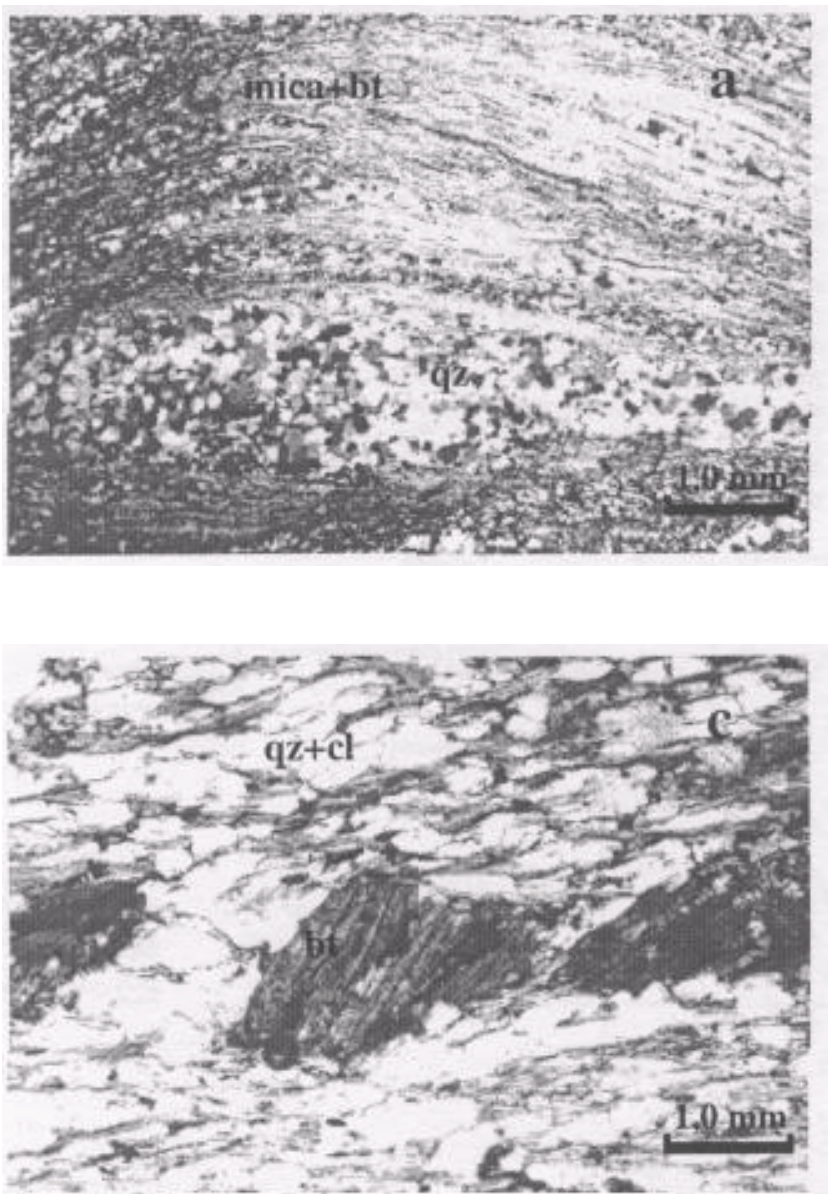

A lineação de estiramento é dada pelo alongamento de quartzo, feldspato e minerais máficos, e tem uma atitude média $18^{\circ} / 219^{\circ}$ (Fig. $4 \mathrm{~b}$ ), indicando um transporte tectônico segundo NE-SW. Ademais, os indicadores cinemáticos (Simpson \& Schmid 1983, Cobbold \& Capais 1987), tais como a assimetria das sombras de pressão, foliação S-C, estruturas micafish, rotação de granada e estaurolita e dobras assimétricas indicam que o transporte tectônico ocorreu com deslocamento do topo NE e, portanto, reverso.

METAMORFISMO As considerações sobre o metamorfismo das rochas da Antiforme Capané serão baseadas nas associacões minerais de pelitos e semipelitos, subordinadamente de rochas vulcânicas máficas e quartzo-feldspáticas.

Parte dos metapelitos do flanco oeste da antiforme contém a paragênese granada + estaurolita \pm cianita \pm quartzo, o que sugere um pico metamórfico de média pressão da fácies anfibolito inferior (Miyashiro 1994). A presença de estaurolita e cianita indica que estas rochas são pelitos normais (Bucher \& Frey 1994) e seu metamorfismo ocorreu a uma pressão superior a 4,5 kbar e uma temperatura superior a $520^{\circ} \mathrm{C}$ (Bucher e Frey 1994, Winkler 1979). A associação mineral daqueles metapelitos mostra efeitos de retrometamorfismo na fácies xisto verde superior durante a formação de $\mathrm{S}_{2}$, como evidenciado pela substituição de estaurolita por clorita e quartzo, os quais também são constituintes da matriz e marcam a $\mathrm{S}_{2}$. A granada manteve-se estável A estaurolita apresenta trilhas de inclusões com minerais diferentes dos da matriz, indicando que o mineral se formou antes da foliação principal $\left(\mathrm{S}_{2}\right)$ que a envolve, possivelmente durante $\mathrm{S}_{1}$.

Nos demais metapelitos, as associações minerais pré- $\mathrm{S}_{2}$ também são indicativas de maior temperatura, com ausência de estaurolita e podem ser agrupadas em duas paragêneses. Uma, no flanco leste, apresenta lamelas bem desenvolvidas de biotita vermelha escura em estruturas micafish, parcialmente re-equilibrada para clorita + mica branca ou mica branca + hematita ou magnetita, os quais marcam a foliação $S_{2}$. Outra, no flanco oeste e zona central da antiforme, a qual contem abundante granada, raramente retrometamorfisada para mica branca, clorita e óxidos de ferro. A manutenção de granada a temperaturas mais
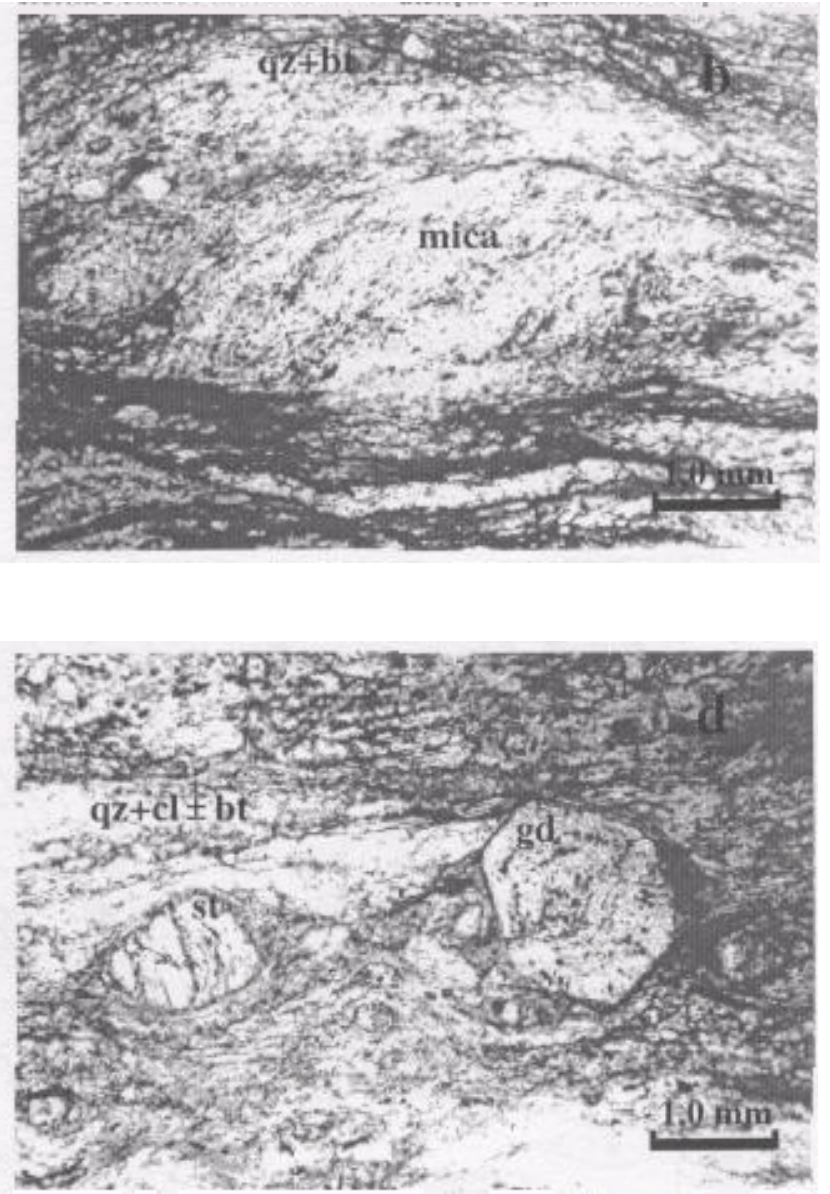

Figura 3 - Micaxistos mostrando (a) textura lepidoblástica e granoblástica, (b) estrutura micafish em mica branca, (c) estrutura micafish em biotita, e (c) granada com textura snow ball (direita) e estaurolita oval (esquerda) com trilhas de inclusões e sombras de pressão, bt - biotita, $\boldsymbol{c l}$ - clorita, gd - granada, mica - mica branca, qz - quartzo, st - estaurolita. 

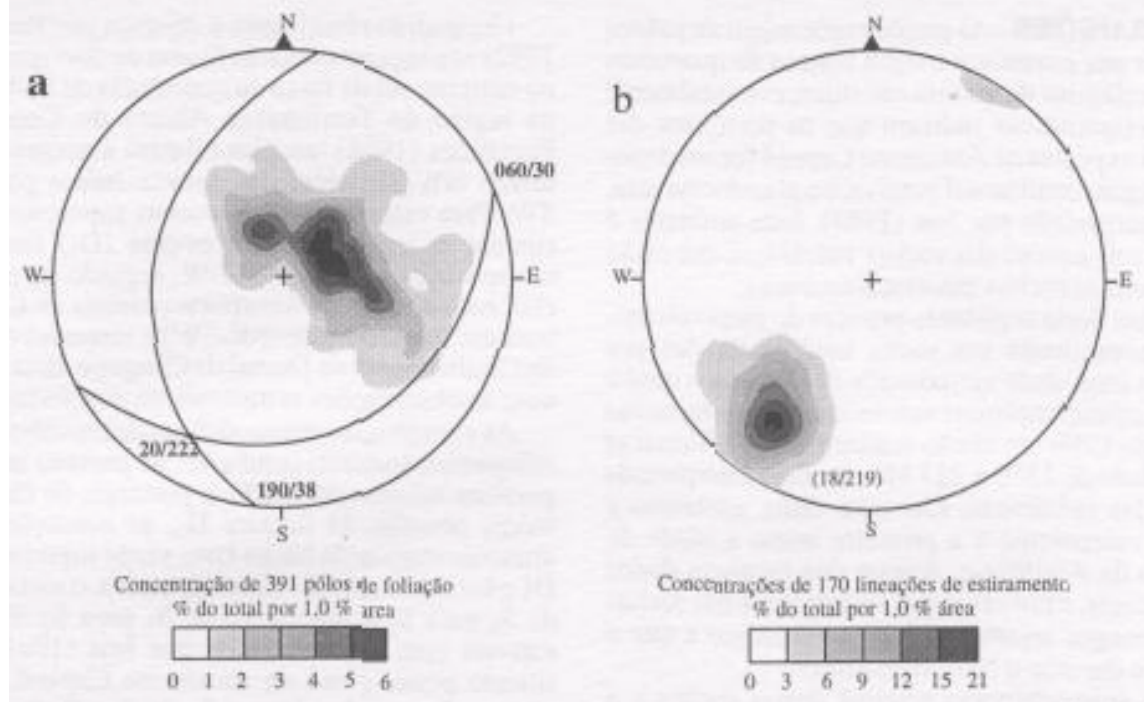

Figura 4 - Diagramas Wolf-Schimdt mostrando (a) pólos defoliações e (b) lineações de estiramento na área da Antiforme Capané.
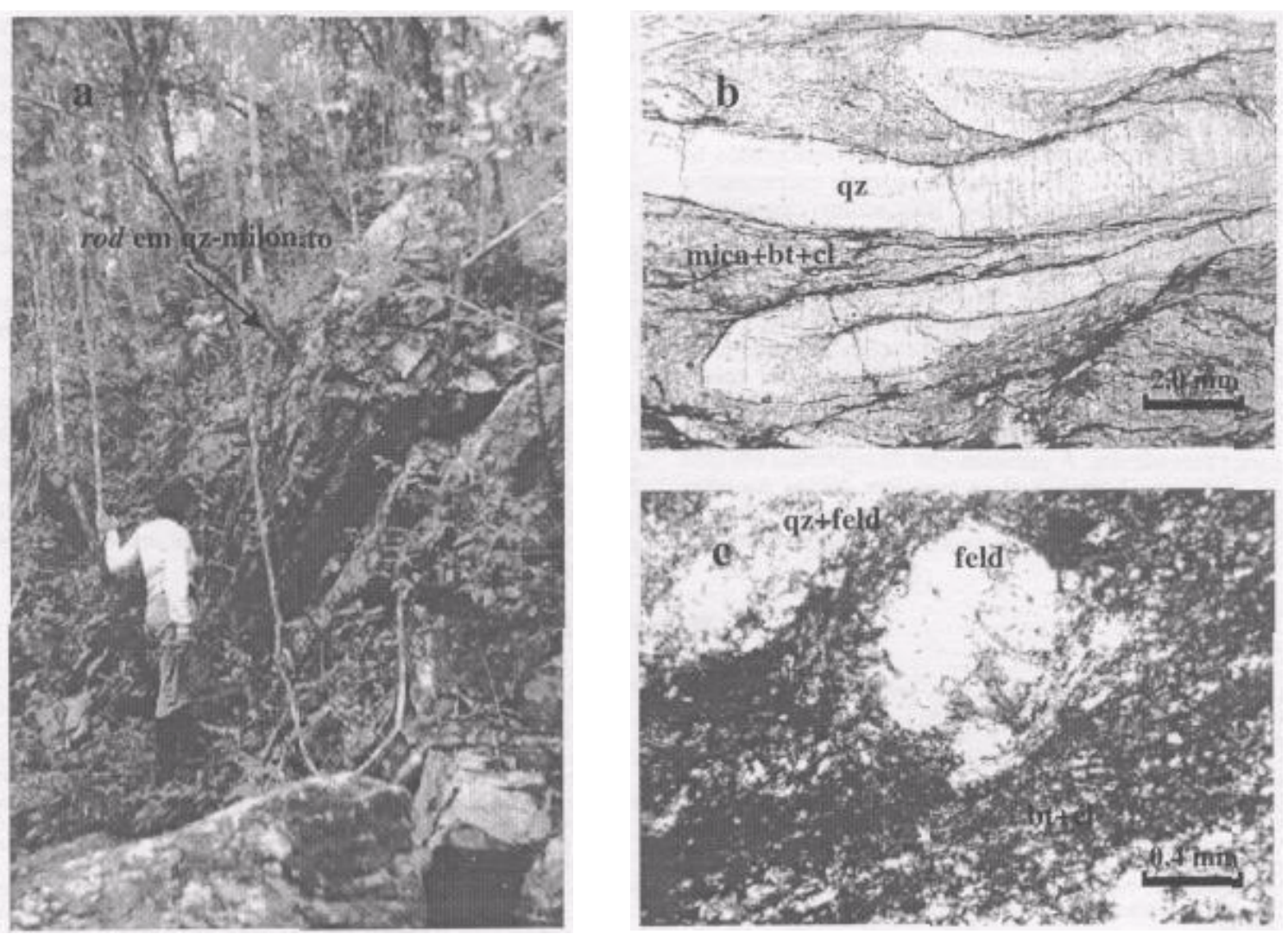

Figura 5 - (a) Rod métrico em quartzito de zona de alto strain, (b) dobras isoclinais em bandas de quartzo em micaxistos, (c) metavulcânica félsica comfenoclasto de feldspato potássico mostrando margens recristalizadas. bt- biotita, cl- clorita, feld-feldspato potássico, mica - mica branca, $\boldsymbol{q z}$ - quartzo.

baixas pode ser explicada pela sua composição, pois, segundo Bucher \& Frey (1994), uma granada com menor quantidade da molécula de almandina pode ser estável a temperaturas da ordem de até $450^{\circ} \mathrm{C}$, já na fácies xisto verde. A ausência de estaurolita e cianita nestes metapelitos pode significar que os protólitos aluminosos não eram pelitos verdadeiros, mas semipelitos, ou que as condições de pico metamórfico (pré-S $S_{2}$ ) foram inferiores às do flanco oeste.

As rochas vulcânicas máficas, restritas ao flanco oeste, apresentam ferroactinolita associada com epidoto, clorita e/ou biotita (Marques 1996, Marques et al. 1998), os quais marcam a foliação $S_{2}$ e indicam fácies xisto verde médio a alto e pressão inferior a 5 kbar e temperatura entre $300 \mathrm{e} 450^{\circ} \mathrm{C}$.

Por outro lado, os xistos localizados próximos ao núcleo da antiforme contém apenas clorita e biotita, com ausência de granada, indicando metamorfismo na fácies xisto verde inferior a médio.
O metamorfismo das rochas quartzo-feldspáticas foi avaliado apenas por meio de microestruturas. A presença de mirmequitas, rotação de subgrãos e recristalização de feldspatos (Marques 1996, Marques et al. 1998) sugerem condições da fácies anfibolito inferior. A formação de mica branca e a segregação de quartzo em quartzitos sugerem que condições de fácies xisto verde durante a geração de $\mathrm{S}_{2}$.

No flanco leste da antiforme, junto à zona de charneira, predominam rochas de mais baixo grau metamórfico e menor deformação, como indicam os filitos e ardósias daquela região. Já os mármores associados apresentam deformação dominantemente rúptil, localmente dúctil. Estas rochas apresentam apenas dobras abertas e kink bands, o acamadamento $\left(\mathrm{S}_{0}\right)$ está melhor preservado e a presença apenas de clorita indicam que o metamorfismo ocorreu nas condições da fácies xisto verde inferior. 
DISCUSSÃO E CONCLUSÕES O amplo predomínio de pelitos e semipelitos, intercalados por estreitos e longos bancos de quartzitos e lentes de mármore com relíquias de textura micrítica, eventualmente também conglomerados oligomíticos indicam que os protólitos das rochas metassedimentares expostas na Antiforme Capané foram depositados em uma ampla margem continental passiva, ou plataforma rasa, como já anteriormente interpretado por Jost (1984). Este ambiente é compatível com o caráter sub-aquoso das rochas vulcânicas que estão intimamente associadas com as rochas metassedimentares.

As únicas rochas datadas nesta sequência provém de metavulcânicas. Datações $\mathrm{Rb} / \mathrm{Sr}$ convencionais em rocha total realizadas por Soliani Jr. (1986) geraram uma idade aproximada de $800 \mathrm{Ma}$, a qual o autor interpreta como a de cristalização das vulcânicas. Contudo, novas determinações pelo método $\mathrm{U} / \mathrm{Pb}$ em zircão realizadas por Wildner $e t$ al (1996) geraram uma idade de $1356 \pm 227$ Ma, também interpretada como a de cristalização das vulcânicas. Em vista disto, adotamos a última como a idade do vulcanismo e a primeira como a idade do metamorfismo das rochas da Antiforme. Apesar dos escassos dados geocronológicos mais precisos, é provável que os protólitos das rochas da Suite Metamórfica Porongos sejam do Mesoproterozóico e que o seu metamorfismo ocorreu durante o Neoproterozóico.

$\mathrm{O}$ paralelismo entre o acamadamento original destas rochas e a proeminente foliação composta, não apenas indica transposição generalizada quanto também que as dobras para as quais $\mathrm{S}_{2}$ era a superficie axial foram isoclinais. $\mathrm{O}$ desenho de $\mathrm{So} / \mathrm{S}_{2} \mathrm{em}$ uma antiforme suave, somado à ocorrência de estreitas e extensas zonas de milonitos e ultramilonitos paralelas à orientacão axial da antiforme indicam que após a formação das dobras isoclinais, houve transporte tectônico da sequência, provavelmente na forma de nappes, se considerados os baixos mergulhos de $\mathrm{So} / / \mathrm{S}_{2}$. A atitude das lineações de estiramento e o sentido de movimento oferecido pelos indicadores cinemáticos indicam que o transporte tectônico deu-se de SW para NE e paralelo ao Cinturão Dom Feliciano. Provavelmente o encurtamento crustal res-ponsável pelas dobras isoclinais foi também responsável pelo movimento tangencial reverso, segundo uma deformação progressiva. O paralelismo entre os eixos de dobras e as lineações de estiramento sugerem que a substituição de dobramentos isoclinais, por encurtamento crustal, e sua evolução para descolamentos de porte e transporte tectônico pode ter sido acompanhada de rotação generalizada das feições estruturais precedentes. A estrutura-ção da sequência em uma ampla e suave antiforme, com a qual se associam dobras parasitas geometricamente similares, com superfície axial marcada por uma clivagem de crenulação espaçada, representam os estágios finais da deformação.
Um padrão semelhante é descrito por Porcher \& Fernandes (1990, 1992) nas supracrustais do Domo de Santana e por Remus et al. (1991) no extremo sul da faixa de ocorrência da Suíte Metamórfica Porongos, na região de Torrinhas e Aberto do Cerro. Contudo, ,Porcher \& Fernandes (1994) também relatam a presença de lineacôes de estiramento NW-SE, além das características posicionadas segundo NESW. Para estes autores, as rochas supracrustais brasilianas da região contém o registro de um evento $\left(\mathrm{D}_{1}\right)$ tangencial com direcão de transporte possivelmente E-W, seguido de outro $\left(\mathrm{D}_{2}\right)$ que foi tangencial, com direção de transporte paralela ao Cinturão Dom Feliciano, e também transcorrente (NE-SW) e responsável pela formação da Zona de Cisalhamento da Dorsal de Canguçu. Esta interpretação não conflita com as observações estruturais na Antiforme Capané.

As paragêneses metamórficas desenvolvidas durante $\mathrm{D}_{1}$, ainda que reliquiares, indicam condições de pressão mínima de $4,5 \mathrm{kbar}$ a temperatura mínima de $520^{\circ} \mathrm{C}$ e, portanto, de fácies anfibolito inferior de média pressão. Já durante $\mathrm{D}_{2}$, as condições de metamorfismo não ultrapassaram as da fácies xisto verde superior. Considerando que entre $\mathrm{Dl}$ e D2 a deformação foi progressiva, o metamorfismo foi progressivo de $S_{0}$ para $S_{1}$, e regressivo de $S_{1}$, para $S_{2}$. Estas condições são compatíveis com as observadas por Jost (1981) no Domo de Santana, situado pouco a sul da Antiforme Capané, mas contrastam com as observadas na Antiforme Serra dos Pedrosas, onde a presença de cordierita e andaluzita indicam metamorfismo na fácies anfibolito inferior, mas de baixa pressão, seguido de retrometamorfismo na fácies xisto verde (Jost 1981, Marques \& Caravaca 1994). Condições de metamorfismo semelhantes às da Antiforme Capané também são relatadas por Remus et al. (1991) no extremo sul da Suíte Metamórfica Porongos, onde a presença de cianita indica metamorfismo sob pressão intermediária, com aumento do grau metamórfico para oeste, onde atinge a fácies anfibolito.

Do exposto se conclui a estreita faixa da Suíte Metamórfica Porongos situada entre os extensos maciços granito-gnáissicos de leste e as rochas sedimentares eo-paleozóicos da porção central do assim denominado "Escudo Sul-Riograndense" não diferem em associacão de rochas, significado paleogeográfico, feições estruturais e condições de metamorfismo.

Agradecimentos Ao Conselho Nacional de Desenvolvimento Científico e Tecnológico - CNPq pelas bolsas, ao Instituto de Geociências da Universidade Federal do Rio Grande do Sul pelo suporte financeiro para trabalhos de campo, ao geólogo Gérson Caravaca e ao bolsista de Iniciação Científica/PIBIC Ivan de Andrade Oliveira pela participação no projeto e a dois revisores anônimos da RBG pelas críticas e sugestões.

\section{Referências}

Bucher, K.; Frcy, M. 1994. Petrogenesis of Metomorphic Rocks, Complete Revision of Winkler's Textbook. 6 ed. Berlin-Germany, Springer-Verlag. 318p.

Camozzato, E.: Sander, A· Ramgrab, G.E.; Wildner, W. 1994. Milonitos alcalinos-peralcalinos da região de Candiota, RS. In: SBG, Congresso Brasileiro de Geologia, 38, Balneário Camboriú-SC, Boletim de Resumos Expandidos, 3:89-90

Cobbold, P.R.; Gapais, D. 1987. Shear criteria in rocks: na introductory review. Journal of Structural Geology, 9(5/6):521-523

Fernandes, L.A.D.; Tommasi, A.; Porcher, C.C. 1990. Esboço Estrutural de parte do Batólito de Pelotas, Região de Quitéria-Capivarita. Acta Geológica Leopoldensia, 30:117-138

Fernandes, L.A.D.; Tommasi, A.; Porcher, C.C. 1992. Deformation patters in the southern brazilian branch of Dom Feliciano belt: a reappraisal. Journal of South American Earth Sciences, 5:77-96

Hartmann, L.A.; Jost, H. 1980. Gnaisses alcalinos da Antiforme Capané. Acta Geológica Leopoldensia, 4(7): 13-25

Jost, H. 1981. Geology and metallogeny of the Santana da Boa Vista region southern Brasil. University of Georgia, Athens, PhD Thesis. 208p.

Jost, H.; Bitencourt, M.F. 1980. Estratigrafia e tectônica de uma fração da faixa de dobramentos de Tijucas no Rio Grande do Sul. Acta geológica Leopoldensia, 7(6):27-60

Jost, H. 1984. Sedimentação e vulcanismo durante o Ciclo Brasiliano no Rio Grande do Sul: uma revisão. SBG, Congresso Brasileiro de Geologia, 33, Anais.., pg.: 3241-3257

Marques, J.C. 1996. Petrologia e Metalogênese da Sequência Metaultramáfica da Antiforme Capané, Suite Metamórfica Porongos, Cachoeira do Sul-RS. Curso de Pós-Graduação
em Geociências, Universidade Federal do Rio Grande do Sul, Porto Alegre, Dissertação de Mestrado, 196p.

Marques, J.C., Jost, H., Roisenberg, A., Teixeira, R.S. 1998. Eventos (gneos da Suíte Metamórfica Porongos na área da antiforme Capané, Cachoeira do Sul - RS. Revista Brasileira de Geociências, 28 (aceito com pequenas revisões / junho de 1998).

Marques, J.C.; Roisenberg, A.; Jost, H. 1996. Cromoespinélio como indicador petrogenélico, Suíte Ultramáfica Cerro da Mineração (SUCM) - Antiforme Capané, Cachoeira do Sul-RS. In: SBG, Cong. Brás. Geol.,39, Salvador, Anais, 6:221-223

Marques.J.C.; Caravaca.G. 1994. Eventos Tectono-Metamórficos do Complexo Cerro da Árvore, Suíte Metamórfica Porongos, Encruzilhada do Sul-RS. In: SBG, Congr. Brás. Geol., 38, Balneário Camboriú, Boletim de Resumos Expandidos, 2:73-74

Miyashiro, A. 1994. Metamorphic Petrology. London, UCL press, King's Lynn and Guildford. $404 \mathrm{p}$.
Porcher, C.C. 1992. Caracterização das Condições de Fluxo em uma Zona de Cisalhamento Tangencial na Região de Santana da Boa Vista. Curso de Pós-Graduação em Geociências, Universidade Federal do Rio Grande do Sul, Porto Alegre, Dissertação de Mestrado, 192p.

Porcher, C.C.; Fernandes, L.A.D. 1990. Relações embasamento/"cobertura" na porção ocidental do cinturão Dom Feliciano: um esboço estrutural. Pesquisas, 17(1/2):72-96

Porcher, C.C.; Fernandes, L.A.D. 1992. Determinação das Condições de Fluxo em uma Zona de Cisalhamento Tangencial com Transporte Paralelo ao Alongamento do Cinturão Dom Feliciano (RS) com Base na Análise de Microestrutura. In: SBG, Congresso Brasileiro de Geologia, 37, São Paulo, Boletim de Resumos Expandidos, 2:352-353

Porcher, C.C.; Fernandes, L.A.D. 1994. Zoneamento metamórfico da Suíte porongos, RS: uma discussão. In: SBG, Congresso Brasileiro de Geologia, 38, Balneário Camboriú, Boletim de Resumos Expandidos, 1:275-277

Remus, M.V.D.; Faecini, U.P".; Tedesco, M.A.; Philipp, R.P. 1987. Evolução estrutural dos metamorfitos da unidade Porongos a sul do Rio Camaquã. In: SBG, Simpósio Sul-brasileiro de Geologia, 3, Curitiba, Atas, 1:223-243

Remus, M.V.D.; Hartmann, L.A.; Ribeiro, M. 1991. Nota sobre a geologia dos metamorfitos de pressão intermediária e granitóides associados da região de Pinheiro Machado/RS. Acta Geológica Leopoldensia, 14(34): 175-190

Santos, E.L.; Ramgrab, G.E.; Maciel, L.A.; Mosmann, R. 1989. Mapa Geológico do estado do Rio Grande do Sul e parte do escudo Sul-rio-grandense. DNPM- $1^{\circ}$ Distrito Regional.

Simpson, C.; Schmid, S.M. 1983. An evaluation of criteria to deduec the sense of movement in sheared rocks. Geológical Society of America Bulletin, 94:1281 -1288

Soliani Júnior, E. 1986. Os Dados Geocronológicos do Escudo Sul-rio-grandense e suas Implicações de Ordem Geotectônica. Inst. de Geociências, Universidade de São Paulo, São Paulo, Tese de Doutoramento, 239p.

Wildner, W.; Camozzato, E.; Orlandi Filho, V.; Basci, M.A.S. 1996. Rochas vulcanogênicas do Cinturão Metamórfico Porongos na Antiforme do Godinho, região do Passo da Cuia-RS. In: SBG, Congresso Brasileiro de Geologia, 39, Salvador, Anais, 2:146-148.

Winklcr, H. 1979. Petrogenesis of Metamorphic Rocks. 5 ed. New York, Springer-Verlag. 348p.

Manuscrito À-972

Recebido em 25 de marco de 1998 Revisão dos autores em 25 de julho de 1998 Revisão aceita em 30 de julho de 1998 